\title{
Regulation of human resistin gene expression in cell systems: an important role of stimulatory protein 1 interaction with a common promoter polymorphic site
}

Received: 6 August 2004 / Accepted: 20 January 2005 / Published online: 30 April 2005

(C) Springer-Verlag 2005

\begin{abstract}
Aims/hypothesis: Resistin is an adipokine that might link obesity and insulin resistance. A common polymorphism of the human resistin gene, $-420 \mathrm{C}>\mathrm{G}$, is a major determinant of plasma resistin concentrations as well as resistin mRNA expression in human adipose tissue. In this study, we investigated the regulatory mechanism by which this polymorphism affects resistin expression. Methods: Electrophoretic mobility shift assay was performed to identify the transcription factors binding to the $-420 \mathrm{G}$ region. Transient transfection and reporter assay were used to measure promoter activities of the resistin gene. The binding ability of stimulatory protein $1(\mathrm{Sp} 1)$ in response to adipocyte differentiation or high glucose concentrations was also measured. Results: Sp1 and stimulatory protein 3 (Sp3) specifically bound to the region around $-420 \mathrm{G}$ of the human resistin gene. Overexpression of Sp1 increased the promoter activity regardless of -420 genotypes, while the promoter activity of the $-420 \mathrm{G}$ construct was two-fold higher than that of the $-420 \mathrm{C}$ construct. In contrast, overexpression of Sp3 scarcely increased the promoter activity. The binding ability of Sp1 to the $-420 \mathrm{G}$ region was increased in response to adipocyte differentiation. Mithramycin A, an inhibitor of DNA binding of Sp1, reduced the effect of high glucose on transcription induction of the resistin gene in adipocytes. Conclusions/interpretation: These results sug-
\end{abstract}

Electronic Supplementary Material Supplementary material is available for this article at http://dx.doi.org/10.1007/s00125-0051762-y.

S. S. Chung $\cdot$ H. H. Choi $\cdot$ K. W. Kim · Y. M. Cho $\cdot$ K. S. Park Genome Research Center for Diabetes and Endocrine Disease, Clinical Research Institute, Seoul National University Hospital, Seoul, South Korea

Y. M. Cho $\cdot$ H. K. Lee $\cdot$ K. S. Park $(\bowtie)$

Department of Internal Medicine,

Seoul National University College of Medicine,

28 Yongon-Dong Chongno-Gu,

Seoul, 110-744, South Korea

e-mail: kspark@snu.ac.kr

Tel.: +82-2-20721789

Fax: $+82-2-36768309$ gest that $\mathrm{Sp} 1$ is an important factor regulating transcription of human resistin gene. A common polymorphism of the human resistin promoter, $-420 \mathrm{C}>\mathrm{G}$, is critical for the binding of Sp1 and modulates the transcriptional activity of the resistin gene by changing the binding ability of Sp1. In addition, Sp1 may be involved in the increase of resistin expression by hyperglycaemia.

Keywords Polymorphism $\cdot$ Promoter $\cdot$ Resistin $\cdot \mathrm{Sp} 1 \cdot \mathrm{Sp} 3$

Abbreviations $\mathrm{C} / \mathrm{EBP} \alpha$ : CCAAT/enhancer binding protein $\alpha$. EMSA: Electrophoretic mobility-shift assay . FBS: Fetal bovine serum - KLF4: Kluppel-like factor 4 . PPAR: Peroxisome proliferator-activated receptor $\cdot \mathrm{Sp} 1$ : Stimulatory protein $1 \cdot \mathrm{Sp} 3$ : Stimulatory protein $3 \cdot$ SREBP: Sterol regulatory element binding protein

\section{Introduction}

Resistin is a cysteine-rich secretory polypeptide expressed in adipocytes and belongs to a protein family called resistinlike molecules, which is also known as the found-in-inflammatory-zone family [1-3]. Resistin has been proposed as a potential link between obesity and insulin resistance. It has been reported that the serum levels of resistin are markedly increased in obese mice and are decreased by treatment with thiazolidinediones [4]. The expression of resistin in adipocytes is decreased by fasting and increased by refeeding, and the administration of anti-resistin antibodies increased insulin-stimulated glucose uptake in obese mice. Furthermore, the treatment of normal mice with recombinant resistin impairs glucose tolerance and insulin action [4]. The transgenic overexpression of resistin impairs skeletal muscle glucose metabolism and promotes glucose intolerance [5]. In contrast, some reports demonstrate that a high level of resistin is not related to obesity or insulin resistance [6-8]. In particular, several studies with human resistin do not show any association between resistin expression and insulin resistance $[9,10]$. Levels of resistin expression are similar in normal, insulin-resistant and type 2 
diabetic individuals [9]. Recently, however, we observed that plasma resistin levels were elevated in patients with type 2 diabetes compared with those in non-diabetic individuals [11]. Moreover, mice lacking the resistin gene show that resistin plays an important role in the maintenance of blood glucose during fasting, by increasing hepatic glucose production [12]. It has been reported that retinoic acid administration to mice reduces the expression of resistin and improves glucose tolerance [13]. Therefore, resistin may play an important role in insulin resistance or glucose homeostasis.

Many studies show that various hormones and drugs influencing insulin sensitivity regulate resistin mRNA expression in cell culture and animal models [14-17]. Glucose and dexamethasone increase resistin mRNA levels, but insulin, TNF- $\alpha$ and thiazolidinediones suppress the expression of resistin. However, little is known about the regulatory mechanisms of resistin expression by these hormones or drugs. In addition, some transcriptional regulators have been identified as involved in the expression of human or mouse resistin. CCAAT/enhancer binding protein $\alpha(\mathrm{C} / \mathrm{EBP} \alpha)$ and sterol regulatory element binding protein (SREBP) are key regulatory factors for adipocyte-specific expression of resistin $[18,19]$.

There are several reports showing polymorphisms of human resistin gene, and interestingly a common promoter polymorphism of human resistin gene, $-420 \mathrm{C}>\mathrm{G}$, is a major determinant of the mRNA levels of resistin [20]. We also reported that this polymorphism was important in determining plasma resistin levels [21]. In that study, plasma resistin levels of the $-420 \mathrm{G} / \mathrm{G}$ genotype group were higher than those of the $-420 \mathrm{C} / \mathrm{C}$ genotype group. In addition, we showed that the specific transcription factors of the nuclear extracts from adipocytes and monocytes were bound to the $-420 \mathrm{G}$ region with high affinity but not to the $-420 \mathrm{C}$ region [21].

Stimulatory protein $1(\mathrm{Sp} 1)$ is one of the best characterised transcriptional factors, and involved in expression of numerous genes. Sp1 binds to GC or GT boxes in the promoters and stimulates transcription of the target genes [22]. Three other Sp family members, Sp2, Sp3 and Sp4, have been identified. Sp3 is highly homologous to $\mathrm{Sp} 1$ and they have similar affinities for the binding sites. Sp3 stimulates transcription of some genes by working cooperatively with $\mathrm{Sp} 1$, but it can also repress Sp1-mediated transcription of several genes [23-25]. Post-translational modifications, 0 -glycosylation and phosphorylation, of Sp1 modulate the activity of Sp1 [22].

In this study, we investigated the regulatory factors involved in inducing the different resistin levels observed in the $-420 \mathrm{C}>\mathrm{G}$ polymorphism.

\section{Materials and methods}

Plasmids The DNA fragment from -746 to $-211 \mathrm{bp}$ of the human resistin gene was inserted into the region upstream of the luciferase gene of the pGL2-basic vector (Promega, Madison, WI, USA). Based on the nucleotide at -420 , each construct was named RETN (-420G) Luc or RETN (-420C) Luc. The Sp1 and Sp3 expression vectors were generous gifts from Dr I. K. Lee (Keimyung University, Korea) and Dr T. K. Kim (Korea Advanced Institute of Science and Technology, Taejon, Korea), respectively [26, 27].

Cell culture and differentiation The 3T3-L1 adipocytes were maintained in DMEM (Invitrogen, Carlsbad, CA, USA) supplemented with $10 \%$ fetal bovine serum (FBS) (Invitrogen). Differentiation was induced by adding $0.5 \mathrm{mmol} /$ 13-isobutyl-1-methylxanthine, $0.25 \mu \mathrm{mol} / 1$ dexamethasone (Sigma, St. Louis, MI, USA) and $5 \mu \mathrm{g} / \mathrm{ml}$ insulin to the media for $48 \mathrm{~h}$. The cells were maintained in DMEM supplemented with $10 \% \mathrm{FBS}$ and $1 \mu \mathrm{g} / \mathrm{ml}$ insulin for an additional 10 days with the media being changed every other day. The THP-1 monocytes were maintained in RPMI 1640 (Invitrogen,) supplemented with $10 \%$ FBS. The COS7 cells were cultured in DMEM supplemented with $10 \%$ FBS.

Nuclear extracts and electrophoretic mobility shift assay Nuclear proteins were prepared from 3T3-L1 adipocytes, THP-1 monocytes and COS7 cells, as described previously with minor modifications [28]. Double-stranded oligonucleotide representing the -433 to -406 bp region (upper strand sequence: 5'-CTGGACATGAAGAGGGAGGCCC TGTTGG-3'; -420G is underlined) of the resistin gene was labelled with $\left[\alpha-{ }^{32} \mathrm{P}\right] \mathrm{dCTP}$ using Klenow DNA polymerase (Ambion, Austin, TX, USA). The labelled probe $(25,000 \mathrm{cpm})$ was incubated with nuclear proteins $(5 \mu \mathrm{g})$ in $10 \mathrm{mmol} /$ HEPES, pH 7.9, containing $50 \mathrm{mmol} / \mathrm{l} \mathrm{KCl}, 0.1 \mathrm{mmol} / \mathrm{l}$ EDTA, $0.25 \mathrm{mmol} / 1 \mathrm{DTT}, 0.1 \mathrm{mg} / \mathrm{ml}$ poly(dIdC), $0.01 \%$ Nonidet P-40, and $10 \%$ glycerol, at room temperature for 15 min. Antibodies against Sp1 (sc-17824), Sp3 (sc-644), Ikaros (sc-9861) or Kluppel-like factor 4 (KLF4) (sc-01905) (Santa Cruz Biotechnology, Santa Cruz, CA, USA) were incubated with nuclear proteins for $15 \mathrm{~min}$ on ice before the addition of the labelled probe. Competitor oligonucleotides (the -433 to $-406 \mathrm{bp}$ region containing $-420 \mathrm{G}$ or $-420 \mathrm{C}$ ) were added in 100-, 200- or 400-fold molar excesses with respect to the labelled probe. The oligonucleotide containing the consensus Sp1 binding site (upper strand sequence: 5'-GATTCGATCGGGGCGGGGCGAGC TTGG-3'; consensus Sp1 binding site is underlined) was also used as a competitor. The reaction mixtures were separated on 5\% polyacrylamide gel in $0.5 \times \mathrm{TBE}$ buffer and subjected to electrophoresis. The complexes were visualised by autoradiography.

Transient transfection and reporter assay 3T3-L1 or COS7 cells were cultured in DMEM supplemented with $10 \%$ FBS. The cells were transfected in six-well plates using Lipofectamine Plus (Invitrogen). The cells were transfected with a total of $1 \mu \mathrm{g}$ of DNA per well: $0.6 \mu \mathrm{g}$ of the reporter plasmids, $0.25 \mu \mathrm{g}$ of the $\mathrm{Sp} 1$ or $\mathrm{Sp} 3$ expression vectors and $0.15 \mu \mathrm{g}$ of $\mathrm{pCMV}-\beta$-galactosidase. To transfect the same amount of DNA, pcDNA (Invitrogen) was added in place of the $\mathrm{Sp} 1$ or $\mathrm{Sp} 3$ expression vector in the case of the control set. The cells were harvested $40 \mathrm{~h}$ after transfection, and luciferase assays were performed using the luciferase assay 
system (Promega, Madison, WI, USA). The $\beta$-galactosidase activity was measured in order to normalise any variations in the transfection efficiency.

RNA isolation, Northern blots and ELISA 3T3-L1 adipocytes differentiated for 10 days were maintained with low glucose $(5.5 \mathrm{mmol} / \mathrm{l})$ or high glucose $(25 \mathrm{mmol} / \mathrm{l})$ for $48 \mathrm{~h}$. Mithramycin A (100 nmol/l) (Sigma), an inhibitor of Sp1 binding to DNAs [29], was added $24 \mathrm{~h}$ before harvesting cells. Total RNAs were extracted using Trizol (Invitrogen) according to the manufacturer's instructions. Total RNAs $(20 \mu \mathrm{g})$ were separated by electrophoresis and transferred to a Nytran membrane (NY 13-N; Schleicher \& Schuell, Keene, NH, USA). The membranes were prehybridised in QuickHyb hybridisation solution (Stratagene, La Jolla, CA, USA) and then hybridised with probes for mouse resistin or $\beta$-actin labelled with $\left[\alpha{ }^{32} \mathrm{P}\right]$ dATP. The membranes were then exposed to X-ray films. The films were scanned and the band intensities were analysed by the TINA $2.10 \mathrm{~g}$ program (Raytest, Straubenhardt, Germany). The amount
Fig. 1 Binding of Sp1 to the region around $-420 \mathrm{G}$ of the resistin gene promoter. a Schematic diagram of a part of the human resistin gene, indicating a sequence variation at -420 of the resistin gene. b Electrophoretic mobility shift assays. Doublestranded oligonucleotides representing the region from -433 to $-406 \mathrm{bp}$ of the resistin gene were radiolabelled with $\left[\alpha-{ }^{32} \mathrm{P}\right]$-dCTP and incubated without nuclear extracts (lanes 1 and 6 ), with nuclear extracts from 3T3-L1 adipocytes (lanes 2-5) or with nuclear extracts from THP-1 monocytes (lanes 7-10). Approximately $1 \mu \mathrm{g}$ of the antibodies against $\mathrm{Sp} 1$, Ikaros or KLF4 were used for the super-shift experiment. Three specific DNA-protein complexes (bands 1,2 and 3 ) and free probes are indicated. The $-420 \mathrm{G} / \mathrm{C}$ variation-independent band is indicated by an asterisk, and the fact that this band is not related to the $-420 \mathrm{G} / \mathrm{C}$ variation was proven in the previous work [21] a

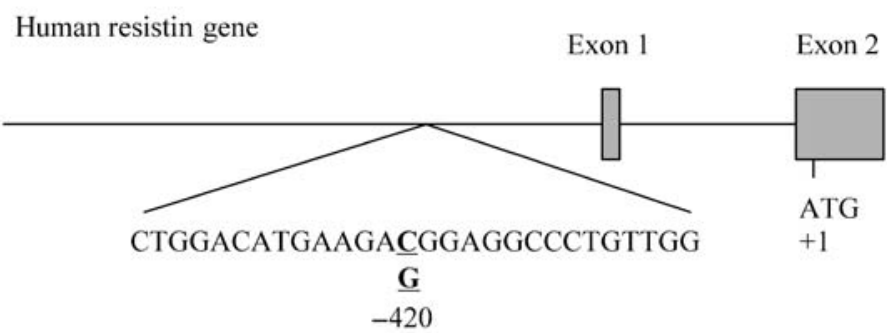

b
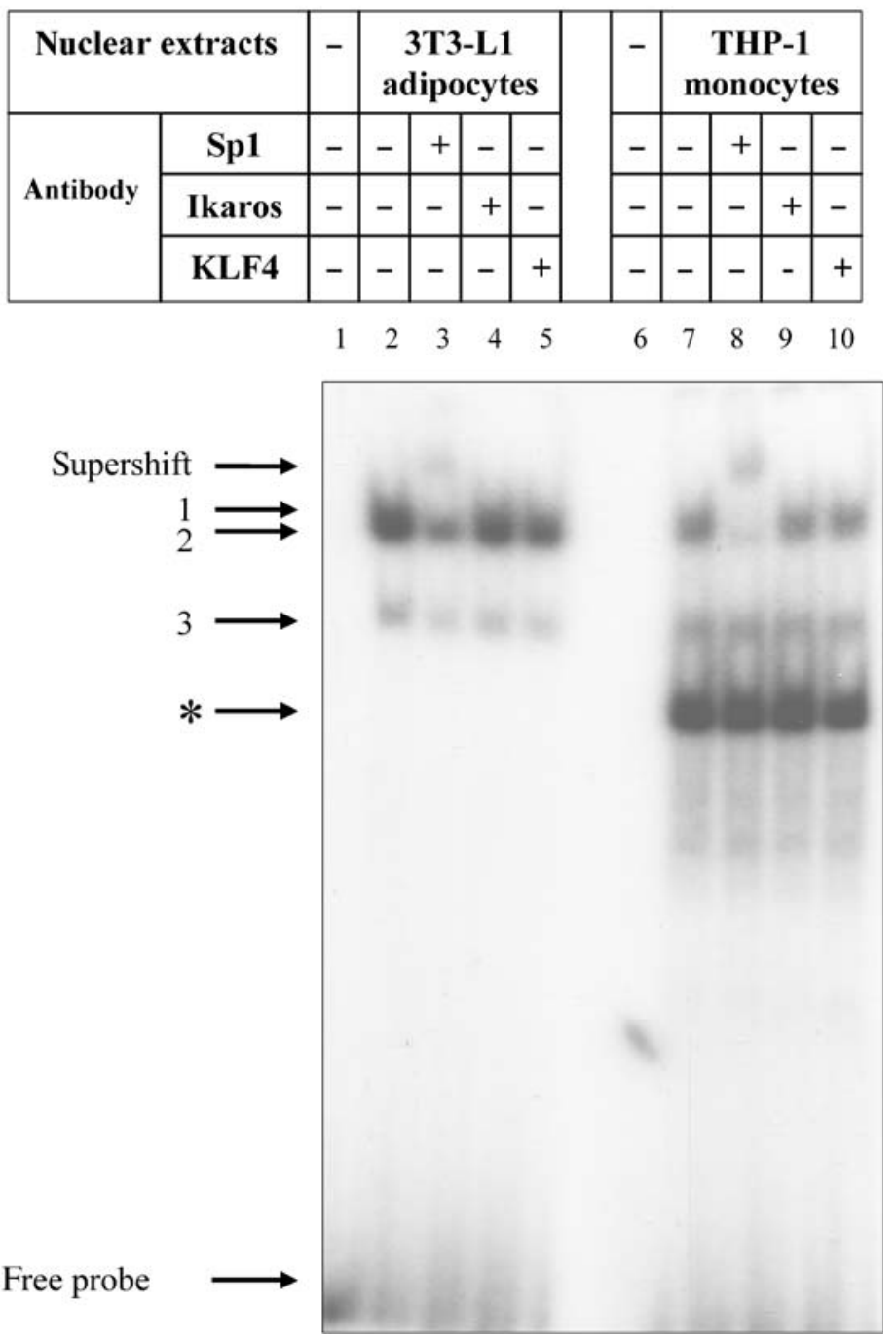
of resistin in the media was measured using a mouse resistin ELISA kit according to the manufacturer's instructions (Komed, Seoul, Korea) [11].

Statistical analysis Statistical differences between experiment groups were determined by Student's $t$-test using InStat (GraphPad Software, San Diego, CA, USA). Values of $p<0.05$ were considered significant.

\section{Results}

Identification of transcription factors bound to the region around $-420 G$ of the resistin gene MatInspector analysis provided several candidate transcription factors that prefer
$-420 \mathrm{G}$ to $-420 \mathrm{C}$ as their binding site, such as Ikaros and KLF4. Since the KLF4 binding motif was similar to the Sp1 binding site, Sp1 was included among the candidate factors. To identify the transcription factors that specifically bind to the $-420 \mathrm{G}$ region, electrophoretic mobility shift assays (EMSAs) were performed using nuclear extracts from 3T3-L1 adipocytes with a probe containing $-420 \mathrm{G}$ in the presence of antibodies against Sp1, Ikaros or KLF4. Antibodies against Ikaros or KLF4 did not affect the binding of the transcription factors to the $-420 \mathrm{G}$ region. In contrast, DNA-protein complex 1 was super-shifted upon the addition of an antibody against Sp1. Since human resistin is expressed mainly in monocytes rather than in adipocytes, we also performed EMSA with THP-1 monocyte nuclear extracts. The addition of antibody against Sp1 also a

\begin{tabular}{|c|l|l|l|l|l|l|l|l|l|l|l|}
\hline $\begin{array}{l}\text { Nuclear } \\
\text { extracts }\end{array}$ & - & \multicolumn{7}{|c|}{ 3T3-L1 adipocytes } \\
\hline Competitor & - & - & $-420 \mathrm{G}$ & \multicolumn{2}{|c|}{$-420 \mathrm{C}$} & \multicolumn{3}{|c}{ Sp1 } \\
\hline & & & 1 & 2 & 4 & 1 & 2 & 4 & 1 & 2 & 4 \\
0 & 0 & 0 & 0 & 0 & 0 & 0 & 0 & 0 \\
0 & 0 \\
0 & - & - & 0 & 0 & 0 & 0 & 0 & 0 & 0 & 0 \\
\hline
\end{tabular}

$\begin{array}{lllllllllll}1 & 2 & 3 & 4 & 5 & 6 & 7 & 8 & 9 & 10 & 11\end{array}$

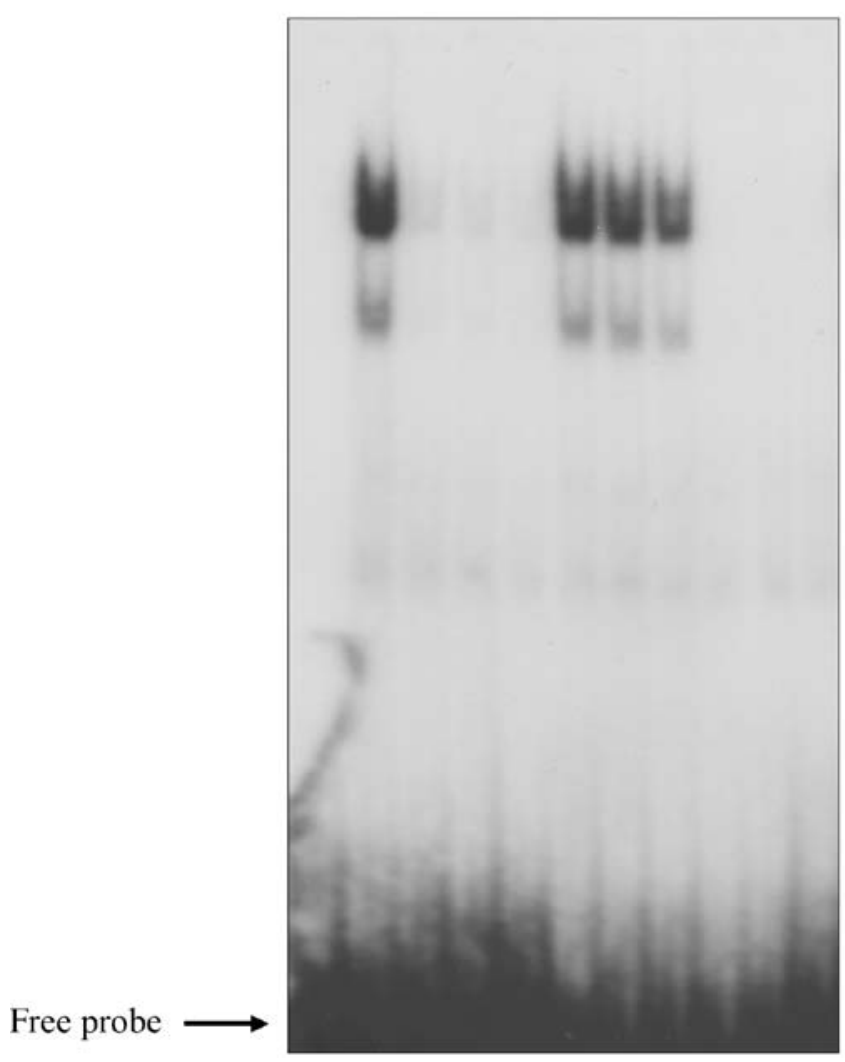

b
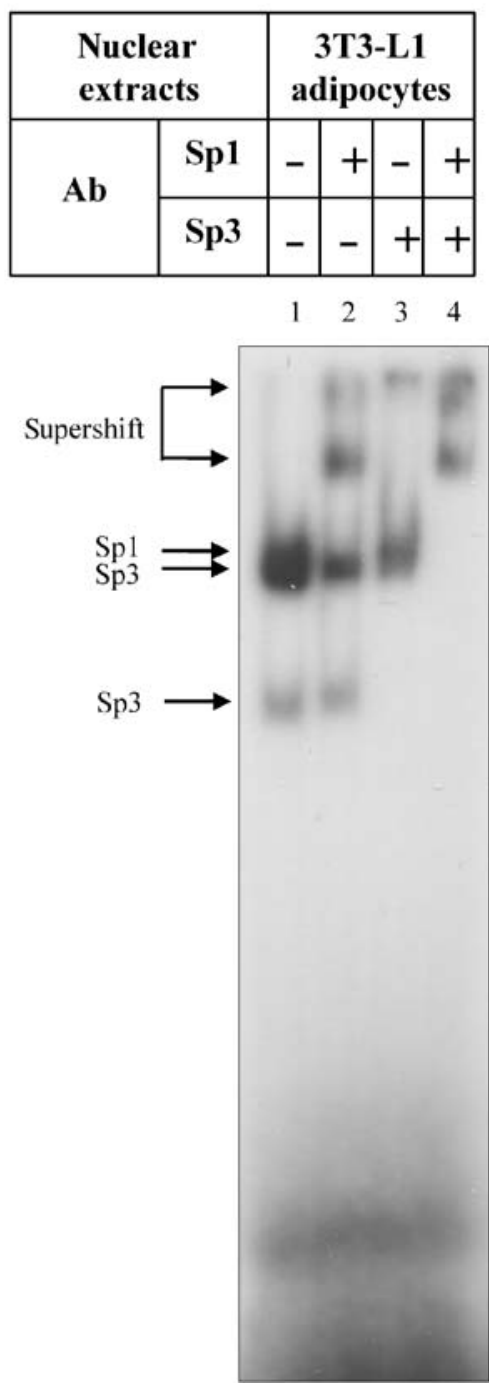

Fig. 2 Sp1 and Sp3 specifically bind to the $-420 \mathrm{G}$ region of the resistin gene. a EMSAs with competitors. Nuclear extracts from 3T3L1 adipocytes were incubated with the same probe as that used in Fig. 1. For the competition assay, unlabelled oligonucleotides containing $-420 \mathrm{G}$ (lanes 3-5), $-420 \mathrm{C}$ (lanes 6-8) or the consensus Sp1 binding site (lanes 9-11) in 100-, 200- or 400-fold molar excesses were used. EMSAs (b) with antibodies against Sp1 and Sp3. Nuclear extracts were incubated with antibodies against Sp1 (lane 2), Sp3 (lane 3) or both (lane 4) for $15 \mathrm{~min}$ before the addition of labelled probes. Super-shifted bands are indicated 
$\mathbf{a}$
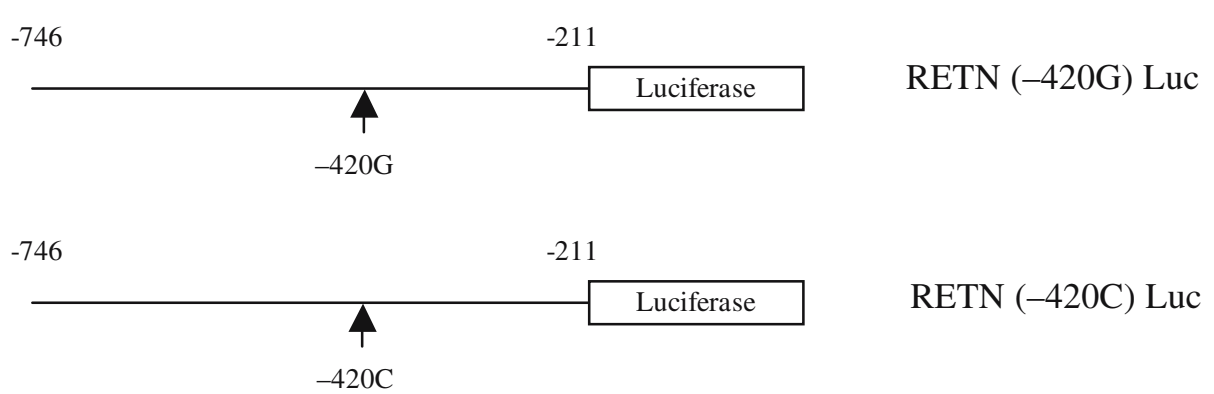

b

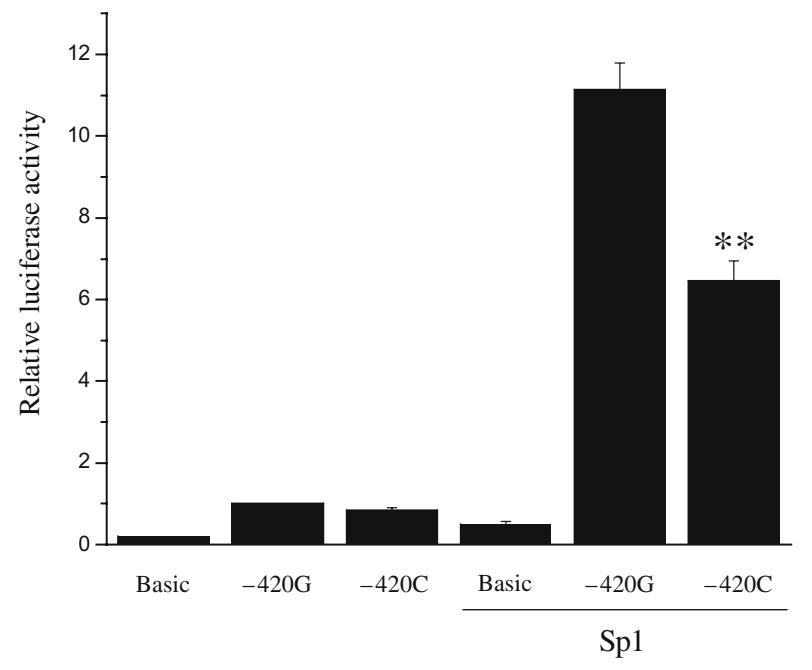

d c

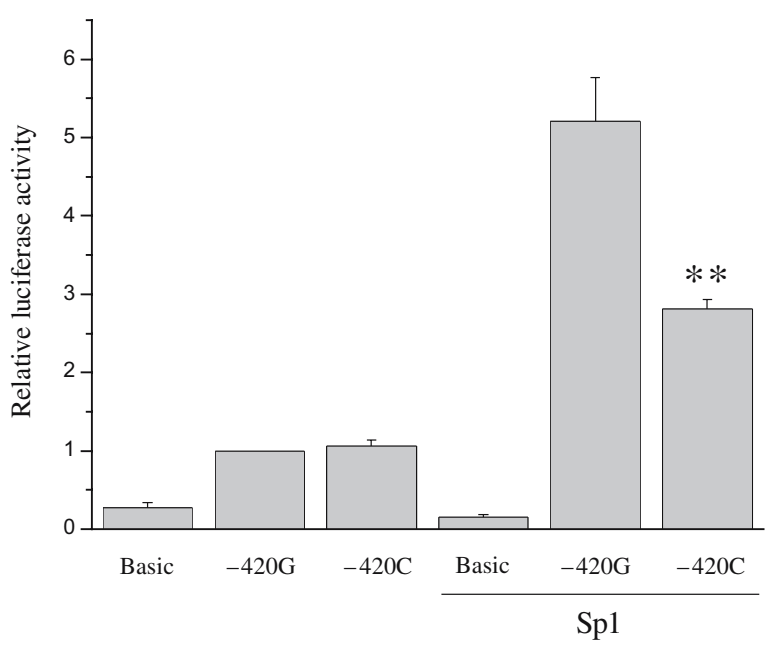

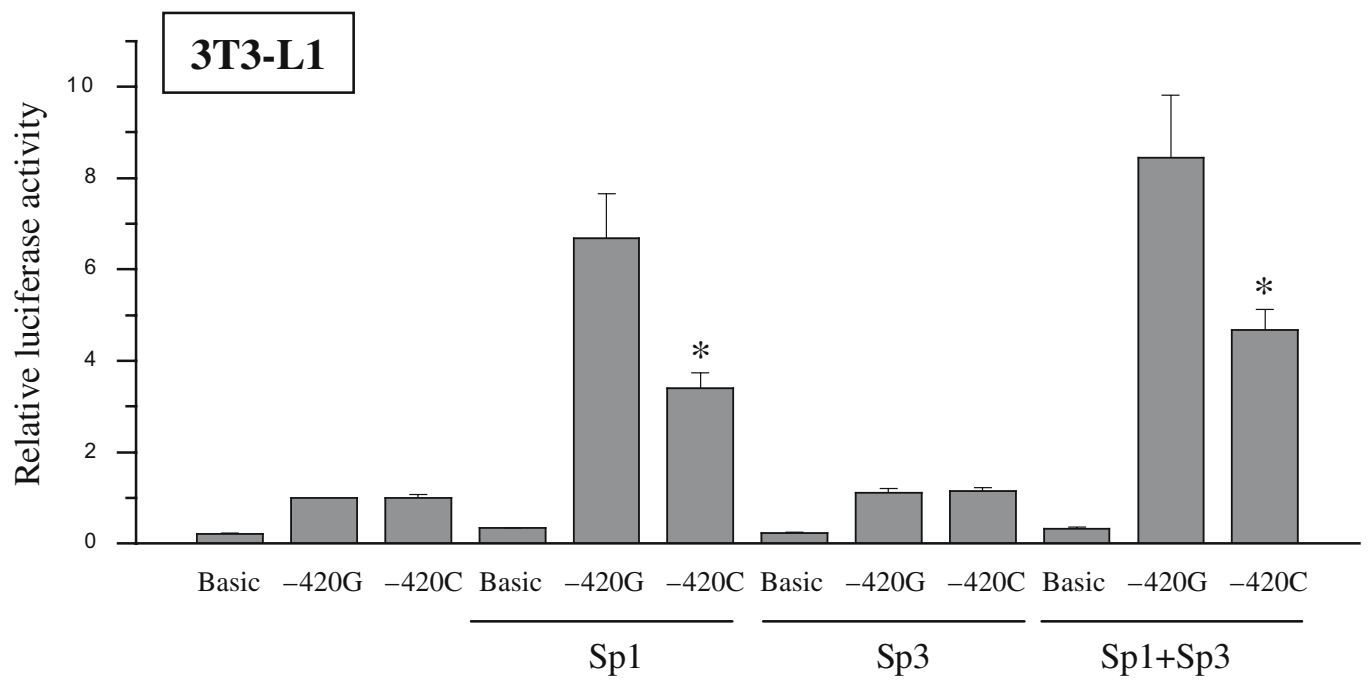

Fig. 3 Effect of overexpression of $\mathrm{Sp} 1$ on the resistin promoter activity. a A DNA fragment representing the region between the $-746 \mathrm{bp}$ and $-211 \mathrm{bp}$ of the resistin gene was inserted into the region upstream of the luciferase coding sequences of the pGL2-basic vector. Each construct containing $-420 \mathrm{G}$ or $-420 \mathrm{C}$ is referred to RETN $(-420 \mathrm{G})$ Luc or RETN (-420C) Luc, respectively. One of the reporter constructs, pGL2-basic, RETN (-420G) Luc or RETN (-420C) Luc, was transfected into 3T3-L1 preadipocytes (b) or COS-7 cells (c) with $\mathrm{Sp} 1$ expression vectors and $\mathrm{pCMV}-\beta$-galactosidase as described (see Materials and methods). Luciferase activity was normalised by $\beta$ galactosidase activity. Luciferase activity of RETN (-420G) in the

absence of $\mathrm{Sp} 1$ overexpression was set to one, and the other activities were expressed relative to this measure. Bars indicate means \pm SEM from seven independent experiments (3T3-L1) or four independent experiments (COS-7). ** $p<0.01$ compared with the value of RETN $(-420 \mathrm{G})$ Luc in the presence of Sp1. d Luciferase reporter constructs were transfected with the $\mathrm{Sp} 1$ and $\mathrm{Sp} 3$ expression vectors or both When the Sp1 or Sp3 expression vector $(0.15 \mu \mathrm{g})$ was transfected alone, empty vectors ( $\mathrm{pCMV}$-vector, $0.15 \mu \mathrm{g}$ ) were added to transfect the same amount of DNA. Bars indicate means \pm SEM from three independent experiments. ${ }^{*} p<0.05$ compared with the value of $R E T N$ $(-420 \mathrm{G})$ Luc in the presence of Sp1 
super-shifted the DNA-protein complex 1 from monocyte nuclear extracts (Fig. 1b).

As shown in Fig. 2a, cold oligonucleotides containing $-420 \mathrm{G}$ (self competitor) but not $-420 \mathrm{C}$ competed well with the probe for the binding of the transcription factors. In addition, the oligonucleotides containing the consensus Sp1 binding sites competed effectively, suggesting that the consensus Sp1 binding site is more susceptible to these transcription factors. Since Sp1 and Sp3 bind to the same DNA sequence, we performed an EMSA with antibodies against Sp1 and Sp3 (Fig. 2b). Different bands were super-shifted upon the addition of antibodies against $\mathrm{Sp} 1$ or $\mathrm{Sp} 3$, and the simultaneous addition of the $\mathrm{Sp} 1$ and $\mathrm{Sp} 3$ antibodies supershifted all of the DNA-protein complexes found in the adipocyte nuclear extracts. Therefore, we concluded that $\mathrm{Sp} 1$ and Sp3 specifically bind to the $-420 \mathrm{G}$ region of the resistin gene.

Transactivation of resistin promoter activity by Sp1 To investigate the effect of the binding of Sp1 to the $-420 \mathrm{G}$ region on the promoter activities, a proximal region of the resistin promoter (from -746 to $-211 \mathrm{bp}$ ) was linked to the luciferase reporter gene of the pGL2-basic vector (Fig. 3a).
The recombinant vectors were transfected into 3T3-L1 preadipocytes or COS-7 cells in the absence or presence of the $\mathrm{Sp} 1$ expression vector. The promoter activities of two constructs, RETN (-420G) Luc and RETN (-420C) Luc, in 3T3-L1 preadipocytes were found to be similar (Fig. 3b). When the Sp1 expression vector was cotransfected, the promoter activity of RETN (-420G) Luc was increased 11fold and that of RETN (-420C) Luc was increased about six-fold in 3T3-L1 preadipocytes (Fig. 3b). There was an approximately two-fold difference between these two constructs in the levels induced by Sp1. When the same constructs were transfected into COS-7 cells, the promoter activity of RETN (-420G) Luc was increased five-fold by cotransfecting it with the Sp1 expression vector (Fig. 3c). In contrast, there was an approximately 2.7 -fold increase in the $\operatorname{RETN}(-420 \mathrm{C})$ Luc.

Since the results obtained from the EMSAs showed that both $\mathrm{Sp} 1$ and $\mathrm{Sp} 3$ bound to the $-420 \mathrm{G}$ region, we examined the role of $\mathrm{Sp} 3$ in the promoter activity. Cotransfection of the Sp3 expression vector scarcely increased the promoter activity of either RETN (-420G) Luc or RETN (-420C) Luc in 3T3-L1 preadipocytes (Fig. 3d) and COS-7 cells (data not shown). We cotransfected the Sp1 and Sp3 expression vec-
Fig. 4 Binding activity of Sp1/ $\mathrm{Sp} 3$ to the $-420 \mathrm{G}$ region in COS7 and 3T3-L1 adipocytes. Nuclear extracts were prepared from COS-7 (lanes 2-5), differentiated adipocytes (lanes 6-9) or preadipocytes (lanes 10-13). Nuclear proteins $(5 \mu \mathrm{g})$ were incubated with the $-420 \mathrm{G}$ probe in the presence of $\mathrm{Sp} 1$ or $\mathrm{Sp} 3$ antibodies. An additional band $\left.{ }^{*}\right)$ was observed in the nuclear extracts from COS-7. Even though the protein was not identified, it may be the same as that found in the nuclear extracts from THP-1 (Fig. 1), whose binding to the probe was not specific to the $-420 \mathrm{G} / \mathrm{C}$ variation
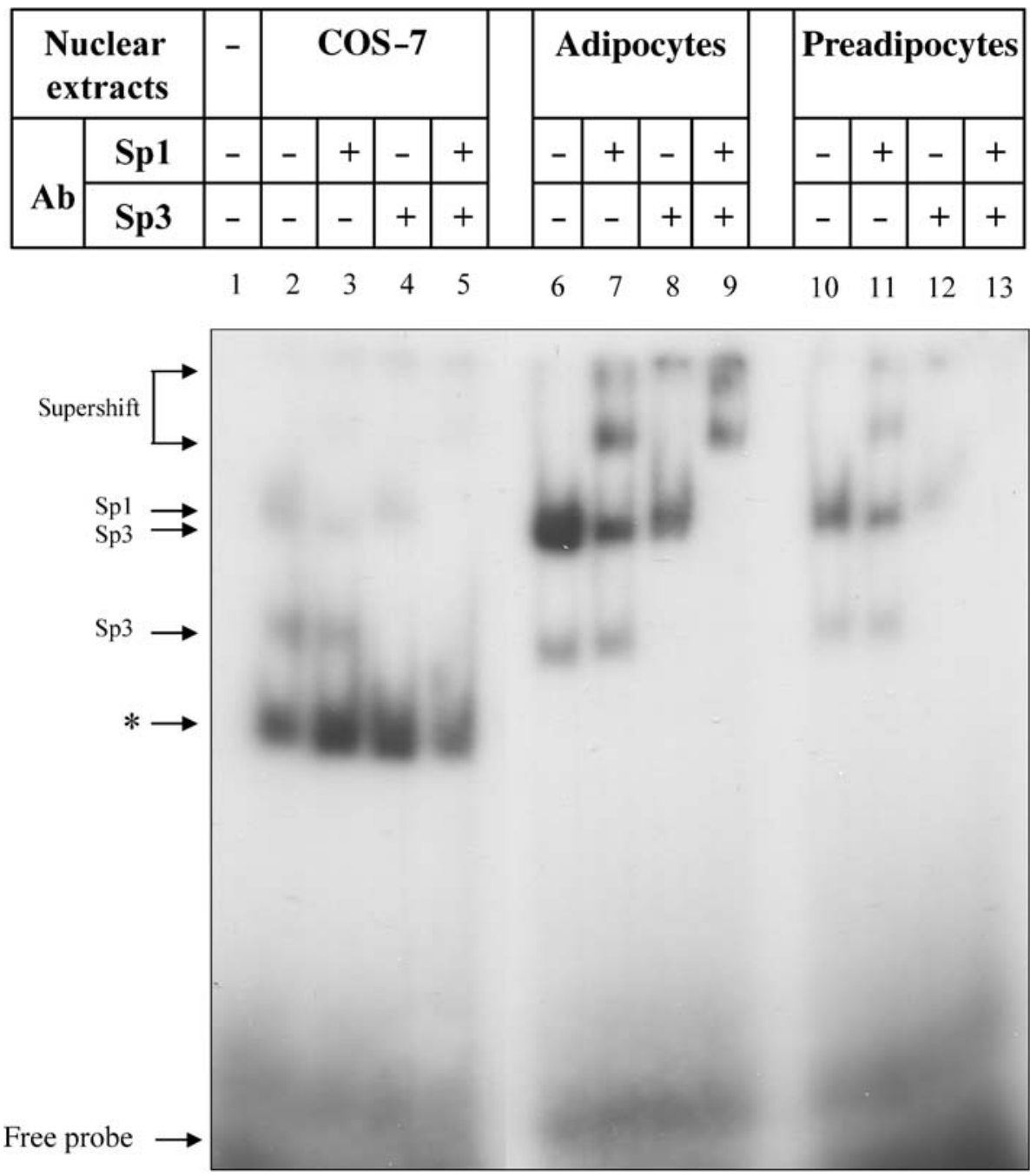
tors simultaneously in order to determine whether there was any interaction between these two transcription factors. The coexpression of Sp3 did not inhibit the effect of Sp1 overexpression on the promoter activity (Fig. 3d).

Binding ability of Sp1/Sp3 in response to differentiation of adipocytes To understand the physiological role of $\mathrm{Spl}$ in relation to the expression of resistin, EMSAs were performed with nuclear extracts from COS-7, 3T3-L1 preadipocytes and differentiated adipocytes. The Sp1 binding affinity of nuclear extracts from differentiated adipocytes was higher than that from COS-7 cells (Fig. 4). In addition, the binding affinity of Sp1 was somewhat higher after differentiation of

a

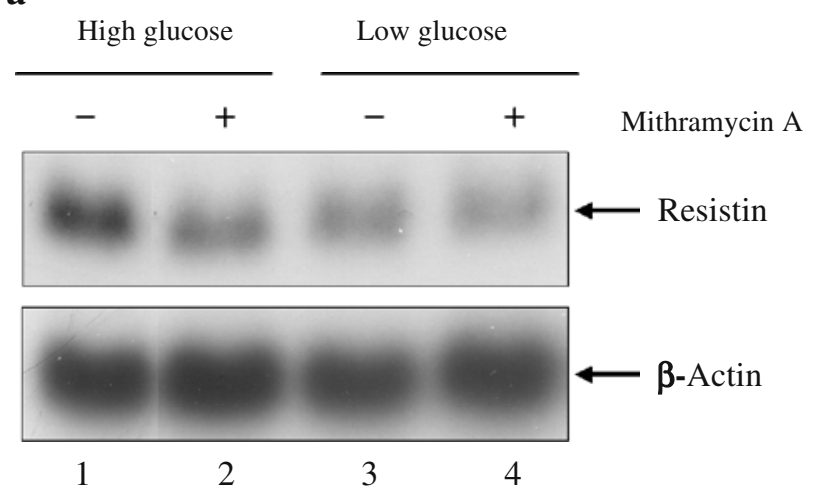

b

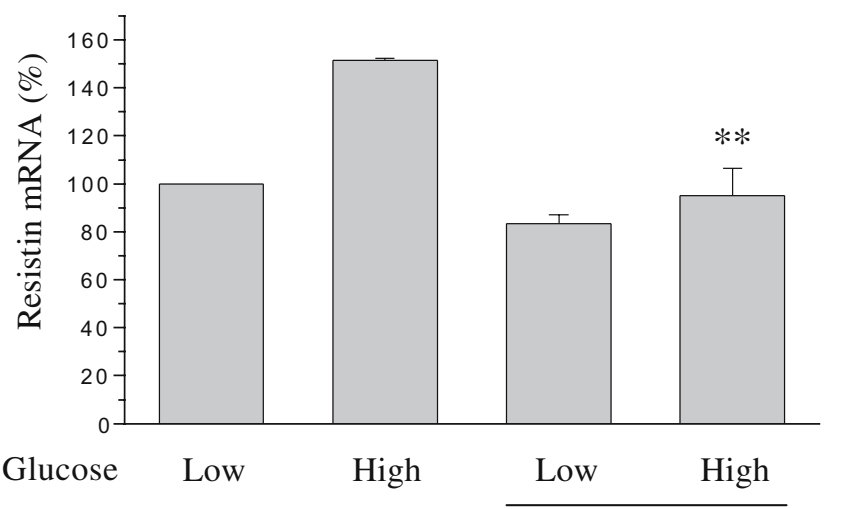

c

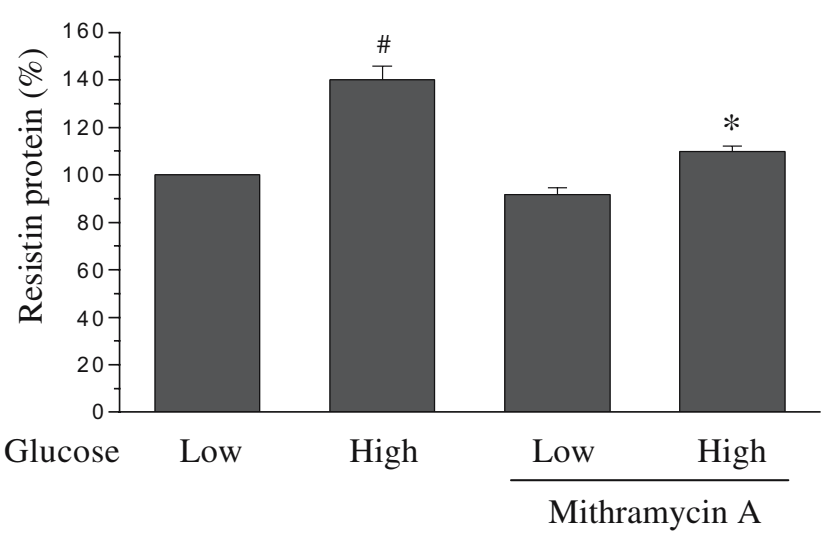

the 3T3-L1 cells. Several transcription factors including peroxisome proliferator-activated receptor (PPAR) $\gamma$, SREBP and $\mathrm{C} / \mathrm{EBP} \alpha$ are involved in adipocyte differentiation. To elucidate whether a specific transcription factor mediates the increase of $\mathrm{Sp} 1$ binding affinity during differentiation, we expressed one of these transcription factors in preadipocytes, and tested the binding affinity of $\mathrm{Sp} 1$. This was not increased by exogenous expression of one of the adipocytespecific transcription factors, PPAR $\gamma, \mathrm{SREBP}$ or $\mathrm{C} / \mathrm{EBP} \alpha$ (Electronic Supplementary Material, Fig. 1), suggesting that the Sp1 binding affinity is not regulated directly by one of these factors.

Effect of mithramycin $A$ on the expression of resistin $\mathrm{We}$ analysed the homology between human and mouse resistin genes in the proximal regions of their promoters. Mouse resistin gene promoter sequence displayed only $49.5 \%$ sequence identity with the human resistin gene promoter, but sequences were conserved in the binding sites for several transcription factors, including $\mathrm{C} / \mathrm{EBP} \alpha$, SREBP and $\mathrm{Sp} 1$ (Electronic Supplementary Material, Fig. 2). Several Sp1 binding sites were found in the mouse resistin gene promoter as well as in the human resistin gene promoter, even though the sites were dispersed differently in the promoters.

To confirm that $\mathrm{Sp} 1$ is involved in resistin expression in differentiated adipocytes, 3T3-L1 adipocytes were treated with mithramycin A, an inhibitor of DNA binding of Spfamily transcription factors. The resistin mRNA level was significantly decreased by the treatment with mithramycin A (lane 1 and 2) (Fig. 5a). Next, we tested whether Sp1 was involved in the regulation of resistin expression by glucose levels. The mRNA level of resistin of the cells maintained with high glucose media $(25 \mathrm{mmol} / \mathrm{l})$ was 1.5 -fold higher than that of the cells maintained with low glucose media (5.5 mmol/l) (Fig. 5a, b). Treatment with mithramycin A almost abolished the effect of glucose on the resistin mRNA levels, indicating that $\mathrm{Sp} 1$ is involved in the glucose-induced regulation of the resistin gene.

Resistin protein levels in the media were determined after treatment with mithramycin A in the presence of low or high levels of glucose. Consistent with the results of northern blot analysis, the resistin protein level was increased 1.4-

Fig. 5 Treatment with mithramycin A inhibited the expression of resistin. a 3T3-L1 adipocytes differentiated for 10 days were maintained with media containing $25 \mathrm{mmol} / \mathrm{l}$ (high) or $5.5 \mathrm{mmol} / \mathrm{l}$ (low) glucose for $48 \mathrm{~h}$. Cells were treated with mithramycin A $(100 \mathrm{nmol} / \mathrm{l})$ for $24 \mathrm{~h}$ before harvesting, and total RNAs were extracted. The levels of resistin or $\beta$-actin mRNA were determined by Northern blot analysis. The Northern blot films were scanned and the band intensities were analysed (b). Bars indicate means \pm SEM from three independent experiments and show percentages of the value of low glucose without mithramycin A. $* * p<0.01$ compared with the value of high glucose in the absence of mithramycin A. c Media were collected from the cells maintained in different concentrations of glucose and treated with mithramycin A, and then the resistin protein levels were measured using a resistin ELISA kit. Bars indicate means \pm SEM from three independent experiments and show percentages of the value of low glucose without mithramycin A. ${ }^{\#} p<0.02$ compared with the value of low glucose in the absence of mithramycin A. ${ }^{*} p<0.05$ compared with the value of high glucose in the absence of mithramycin A 
fold when the cells were maintained in high glucose media (Fig. 5c). After treatment with mithramycin A, the effect of the glucose concentration on the resistin level was significantly reduced.

\section{Discussion}

Several polymorphisms have been found in the promoter region of the resistin gene and it has been reported that one polymorphism, $-420 \mathrm{C}>\mathrm{G}$, was related to plasma resistin levels and diabetes $[20,21,30]$. In this study, we investigated the molecular mechanism underlying the effect of the $-420 \mathrm{G} / \mathrm{C}$ variation on the expression of the resistin gene. The results from the EMSAs suggest that $\mathrm{Sp} 1$ and $\mathrm{Sp} 3$ bind efficiently to the $-420 \mathrm{G}$ region, but not to the $-420 \mathrm{C}$ region. The difference in the plasma resistin levels observed in the case of the polymorphism was reproduced in the promoter activities of the constructs containing $-420 \mathrm{G}$ or $-420 \mathrm{C}$ induced by overexpression of $\mathrm{Sp} 1$. The promoter activity of RETN (-420G) Luc was about two-fold higher than that of RETN (-420C) Luc when the Sp1 expression vector was cotransfected. The difference between these two constructs in both 3T3-L1 and COS-7 shows that Sp1 specifically binds to the $-420 \mathrm{G}$ motif and positively regulates the promoter activity of the resistin gene. In addition, there might be additional Sp1 binding sites in the resistin promoter constructs because cotransfection of the Sp1 expression vector still increased the promoter activity of RETN $(-420 \mathrm{C})$ Luc.

Several studies have shown that $\mathrm{Sp} 1$ and $\mathrm{Sp} 3$ bind to the same DNA sequence and work independently, synergistically or in a mutually inhibitory fashion [31]. In our experiment, $\mathrm{Sp} 3$ overexpression had little effect on the resistin promoter activity. However, since 3T3-L1 and COS-7 cells contain relatively high levels of endogenous $\mathrm{Sp} 3$, we cannot rule out the possibility that the effect produced by transfection of the Sp3 expression vector was not detected in this assay. It could be helpful to use Sp1/Sp3-depleted cells like Drosophila SL2 cells for transfection, even though it has been reported that $\mathrm{Sp} 3$ activates some promoters in Drosophila cells but not in mammalian cells [32]. Cotransfection of Sp3 with Sp1 did not inhibit the Sp1-mediated transcriptional activation, suggesting that $\mathrm{Sp} 3$ is at least not an inhibitory regulator in resistin expression. Even though the role of $\mathrm{Sp} 3$ is obscure, it is clear that $\mathrm{Sp} 1$ plays an important role in regulating resistin expression and is a determinant factor in the induction of different resistin levels according to the $-420 \mathrm{C}>\mathrm{G}$ polymorphism.

Since resistin is produced and secreted from differentiated adipocytes, the expression of the resistin gene should be regulated during differentiation. Resistin expression is regulated by several adipocyte-specific transcription factors, such as C/EBP $\alpha$ and SREBP [19]. Some reports have indicated that the binding ability of Sp1 to the Sp1 binding element in target promoters was increased during the differentiation of adipocytes [33]. They demonstrated that phosphorylation or dephosphorylation of Sp1 determined the binding affinity of Sp1 during adipocyte differentiation. In this study, we showed that the binding ability of Sp1 to the Sp1 binding site $(-420 \mathrm{G})$ of the resistin gene was increased after adipocyte differentiation. The increase of Sp1 binding affinity was not observed by overexpression of PPAR $\gamma$, SREBP or $\mathrm{C} / \mathrm{EBP} \alpha$, which are major transcription factors involved in adipocyte differentiation. Therefore, $\mathrm{Sp} 1$ binding affinity might be determined by a complex process including post-translational modifications during differentiation, rather than directly by a specific transcription factor. Both human and mouse resistin promoters contain several Sp1 binding sites and mithramycin $\mathrm{A}$, an inhibitor of Sp1 binding to DNAs, significantly reduced expression of the resistin gene in mouse adipocytes. Therefore, these results suggest that $\mathrm{Sp} 1$ is an important transcription factor in the regulation of resistin expression in adipocytes; they also explain how the level of resistin is regulated by one base change at -420 in the promoter region in adipose tissues. Since $\mathrm{Sp} 1$ and $\mathrm{Sp} 3$ bindings were detected in nuclear extracts from THP-1 monocytes (Fig. $1 \mathrm{~b}$ and data not shown), which are known to be a major cell type that expresses resistin in humans, Sp1 might be the regulatory factor in these cells as well.

$\mathrm{Sp} 1$ mediates the transcriptional regulation of several genes by means of various external signals. Glucose regulates the promoter activity of several genes via the $\mathrm{Sp} 1$ and Sp1 binding sites [34, 35]. Glucocorticoids and insulin are associated with the expression of some genes through the Sp1 function [36]. The expression of resistin is regulated by several factors, including glucose, insulin, dexamethasone and thiazolidinediones [17]. Therefore, it would be interesting to investigate whether $\mathrm{Sp} 1$ is involved in any transcriptional regulation of the gene caused by these treatments. In this study we tested whether $\mathrm{Sp} 1$ is involved in the regulation of resistin expression by glucose. In the presence of mithramycin A, the effect of glucose on the mRNA and protein levels of resistin was significantly reduced. Sp1 is subjected to post-translational modifications such as glycosylation and phosphorylation [22]. $O$-glycosylation of Sp1 affects the nuclear localisation, stability and transcriptional activity of $\mathrm{Sp} 1$ and phosphorylation regulates the binding activity of Sp1 to the target sequence [22]. It has been reported that hyperglycaemia increases glycosylation of Sp1 and influences the transcriptional activity of $\mathrm{Sp} 1$ [37]. Since resistin expression is increased by hyperglycaemia in rodents, it will be important to find the mechanism by which hyperglycaemia regulates resistin expression. Even though this study did not demonstrate the mechanism by which glucose affected resistin expression, our data suggest it is possible that $\mathrm{Sp} 1$ has a function in the regulation of resistin expression by hyperglycaemia.

In conclusion, the $\mathrm{G} / \mathrm{C}$ variations at -420 of the resistin gene are critical for the binding of Sp1, and modulate the transcriptional activity of the resistin gene by changing the binding ability for Sp1. In addition, Sp1 may be an important factor in regulating transcription of the resistin gene and in mediating the effect of glucose levels.

Acknowledgements This study was supported by a grant from the Korea Health 21 R \& D Project, Ministry of Health \& Welfare, Republic of Korea (00-PJ3-PG6-GN07-001). 


\section{References}

1. Holcomb IN, Kabakoff RC, Chan B et al (2000) FIZZ1, a novel cysteine-rich secreted protein associated with pulmonary inflammation, defines a new gene family. EMBO J 19:4046-4055

2. Kim KH, Lee K, Moon YS, Sul HS (2001) A cysteine-rich adipose tissue-specific secretory factor inhibits adipocyte differentiation. J Biol Chem 276:11252-11256

3. Steppan CM, Brown EJ, Wright CM et al (2001) A family of tissue-specific resistin-like molecules. Proc Natl Acad Sci U S A 98:502-506

4. Steppan CM, Bailey ST, Bhat S et al (2001) The hormone resistin links obesity to diabetes. Nature 409:307-312

5. Pravenec M, Kazdova L, Landa V et al (2003) Transgenic and recombinant resistin impair skeletal muscle glucose metabolism in the spontaneously hypertensive rat. J Biol Chem 278:4520945215

6. Ukkola O (2002) Resistin — a mediator of obesity-associated insulin resistance or an innocent bystander? Eur J Endocrinol 147:571-574

7. Way JM, Gorgun CZ, Tong Q et al (2001) Adipose tissue resistin expression is severely suppressed in obesity and stimulated by peroxisome proliferator-activated receptor gamma agonists. J Biol Chem 276:25651-25653

8. Juan CC, Au LC, Fang VS et al (2001) Suppressed gene expression of adipocyte resistin in an insulin-resistant rat model probably by elevated free fatty acids. Biochem Biophys Res Commun 289:1328-1333

9. Nagaev I, Smith U (2001) Insulin resistance and type 2 diabetes are not related to resistin expression in human fat cells or skeletal muscle. Biochem Biophys Res Commun 285:561-564

10. Savage DB, Sewter CP, Klenk ES et al (2001) Resistin / Fizz3 expression in relation to obesity and peroxisome proliferatoractivated receptor-gamma action in humans. Diabetes 50:21992202

11. Youn BS, Yu KY, Park HJ et al (2004) Plasma resistin concentrations measured by enzyme-linked immunosorbent assay using a newly developed monoclonal antibody are elevated in individuals with type 2 diabetes mellitus. J Clin Endocrinol Metab 89:150-156

12. Banerjee RR, Rangwala SM, Shapiro JS et al (2004) Regulation of fasted blood glucose by resistin. Science 303:1195-1198

13. Felipe F, Bonet ML, Ribot J, Palou A (2004) Modulation of resistin expression by retinoic acid and vitamin A status. Diabetes 53:882-889

14. Li Y, Lazar MA (2002) Differential gene regulation by PPAR gamma agonist and constitutively active PPARgamma2. Mol Endocrinol 16:1040-1048

15. Kawashima J, Tsuruzoe K, Motoshima H et al (2003) Insulin down-regulates resistin mRNA through the synthesis of protein (s) that could accelerate the degradation of resistin mRNA in 3T3-L1 adipocytes. Diabetologia 46:231-240

16. Rajala MW, Qi Y, Patel HR et al (2004) Regulation of resistin expression and circulating levels in obesity, diabetes, and fasting. Diabetes 53:1671-1679

17. Shojima N, Sakoda H, Ogihara Tet al (2002) Humoral regulation of resistin expression in 3T3-L1 and mouse adipose cells. Diabetes 51:1737-1744

18. Hartman HB, Hu X, Tyler KX, Dalal CK, Lazar MA (2002) Mechanisms regulating adipocyte expression of resistin. J Biol Chem 277:19754-19761

19. Seo JB, Noh MJ, Yoo EJ et al (2003) Functional characterization of the human resistin promoter with adipocyte determinationand differentiation-dependent factor $1 /$ sterol regulatory element binding protein 1c and CCAAT enhancer binding protein-alpha. Mol Endocrinol 17:1522-1533
20. Smith SR, Bai F, Charbonneau C, Janderova L, Argyropoulos G (2003) A promoter genotype and oxidative stress potentially link resistin to human insulin resistance. Diabetes 52:1611-1618

21. Cho YM, Youn BS, Chung SS et al (2004) Common genetic polymorphisms in the promoter of resistin gene are major determinants of plasma resistin concentrations in humans. Diabetologia 47:559-565

22. Bouwman P, Philipsen S (2002) Regulation of the activity of Sp1-related transcription factors. Mol Cell Endocrinol 195:2738

23. Bigger CB, Melnikova IN, Gardner PD (1997) Sp1 and Sp3 regulate expression of the neuronal nicotinic acetylcholine receptor beta4 subunit gene. J Biol Chem 272:25976-25982

24. Ko JL, Liu HC, Minnerath SR, Loh HH (1998) Transcriptional regulation of mouse mu-opioid receptor gene. J Biol Chem 273:27678-27685

25. Yu JH, Schwartzbauer G, Kazlman A, Menon RK (1999) Role of the Sp family of transcription factors in the ontogeny of growth hormone receptor gene expression. J Biol Chem 274:3432734336

26. Park KK, Rue SW, Lee IS et al (2003) Modulation of Sp1dependent transcription by a cis-acting E2F element in dhfr promoter. Biochem Biophys Res Commun 306:239-243

27. Won J, Yim J, Kim TK (2002) Sp1 and Sp3 recruit histone deacetylase to repress transcription of human telomerase reverse transcriptase (hTERT) promoter in normal human somatic cells. J Biol Chem 277:38230-38238

28. Dignam JD, Lebovitz RM, Roeder RG (1983) Accurate transcription initiation by RNA polymerase II in a soluble extract from isolated mammalian nuclei. Nucleic Acids Res 11:14751489

29. Blume SW, Snyder RC, Ray R, Thomas S, Koller CA, Miller DM (1991) Mithramycin inhibits SP1 binding and selectively inhibits transcriptional activity of the dihydrofolate reductase gene in vitro and in vivo. J Clin Invest 88:1613-1621

30. Engert JC, Vohl MC, Williams SM et al (2002) 5' flanking variants of resistin are associated with obesity. Diabetes 51:16291634

31. Yu B, Datta PK, Bagchi S (2003) Stability of the Sp3-DNA complex is promoter-specific: $\mathrm{Sp} 3$ efficiently competes with $\mathrm{Sp} 1$ for binding to promoters containing multiple Sp-sites. Nucleic Acids Res 31:5368-5376

32. Hansen TO, Bundgaard JR, Nielsen FC, Rehfeld JF (1999) Composite action of three GC/GT boxes in the proximal promoter region is important for gastrin gene transcription. Mol Cell Endocrinol 155:1-8

33. Zhu Q, Liao K (2000) Differential expression of the adipocyte amino acid transporter is transactivated by SP1 and SP3 during the 3T3-L1 preadipocyte differentiation process. Biochem Biophys Res Commun 271:100-106

34. Marinovic AC, Zheng B, Mitch WE, Price SR (2002) Ubiquitin (UbC) expression in muscle cells is increased by glucocorticoids through a mechanism involving Sp1 and MEK1. J Biol Chem 277:16673-16681

35. Chen YQ, Su M, Walia RR, Hao Q, Covington JW, Vaughan DE (1998) Sp1 sites mediate activation of the plasminogen activator inhibitor-1 promoter by glucose in vascular smooth muscle cells. J Biol Chem 273:8225-8231

36. Lam JK, Matsubara S, Mihara K, Zheng XL, Mooradian AD, Wong NC (2003) Insulin induction of apolipoprotein AI, role of Sp1. Biochemistry 42:2680-2690

37. Du XL, Edelstein D, Rossetti L et al (2000) Hyperglycemiainduced mitochondrial superoxide overproduction activates the hexosamine pathway and induces plasminogen activator inhibitor-1 expression by increasing Sp1 glycosylation. Proc Natl Acad Sci U S A 97:12222-12226 